\title{
Unconditioned Stimulus Pre-exposure Interferes with Conditioned Taste Aversion in Rats
}

\author{
Andrew Chih Wei Huang ${ }^{\star}$ and Sigmund Hsiao \\ Department of Psychology, Fo Guang University, Yi-Lan 26247, Taiwan \\ Department of Psychology, National Chung Cheng University, Chia-Yi, Taiwan
}

\section{Abstract}

Pairing of a gustatory CS and the visceral US induced by lithium chloride ( $\mathrm{LiCl})$ results in reduction of consumption of CS solution. This reduction is termed conditioned taste aversion (CTA). Pre-exposure to CS alone prior to the conditioning disrupts the conditioning (latent inhibition) and so is pre-exposure to US. The US pre-exposure effect is hypothesized to be due to tolerance, habituation, or the associative blocking effect. We studied the dose effect of US pre-exposure on CTA. In 3 experiments, rats were exposed to 10 doses of $\mathrm{LiCl}$ before the CTA procedure that consisted of ingesting a saccharin solution $(0.1 \%)$ followed by injection of a constant dose of $\mathrm{LiCl}(7.632 \mathrm{mg} / \mathrm{rat})$. If the pre-exposure reduced the associability of the US, the CTA should be less. Exp. 1: Pre-exposure to 4 or $8 \mathrm{ml} / \mathrm{kg}$ of $0.15 \mathrm{M} \mathrm{LiCl}, 1,2$ or 4 days prior to CTA did not have effect. Exp. 2: Pre-exposure to 0.5, 1, 2, 16, $32 \mathrm{ml} / \mathrm{kg} 1$-day prior disrupted CTA. Exp. 3: Pre-exposure to 1, 16, 20, 32, $40 \mathrm{ml} / \mathrm{kg}$ 2-days prior disrupted CTA. Summary: (a) The pre-exposure effect was the same whether the pre-exposure occurred 1 or 2 days prior to conditioning. (b) A clear dose-effect relationship existed. (c) The relation was not monotonic. (d) The lowest preexposure dose, $0.5 \mathrm{ml} / \mathrm{kg}$ of $0.15 \mathrm{M} \mathrm{LiCl}$, not strong enough to induce CTA by itself, was effective. (e) Upon repeated pairing of CS and US, CTA became more pronounced. The results do not support the hypotheses mentioned earlier.

\section{Introduction}

The formation of association between two events renders the preceding event the predictive power and the animals' likelihood of avoiding aversive stimuli and obtaining the objects that sustain life and the species is increased. Contiguity and contingency are conditions essential for two or more events to become associated. The former denotes the proximity in space and time between two events, while the later denotes the likelihood of occurrence of one event when the other has occurred. The two conditions, while necessary, do not guarantee an association to form, however. Animals' previous experience with the event also influences the formation. This research is about the effect of pre-exposure to one of the events, the one to be predicted, and the change in its associability.

In his Science article [40], Skinner stresses that the formation of stimulus (S) and response (R) relationship is based on the third event, namely, the consequence, or reinforcement. This principle is known as "three-term contingency". For example, an animal encountering a tastant ( $\mathrm{S}$ ), ingesting it (R) and becoming sick (reinforcement) is an episode containing three-term contingency. The result is that the gustatory stimulus of the tastant becomes connected to the response of ingestion and, henceforth it guides its ingestion. In this case, the $\mathrm{S}-\mathrm{R}$ relationship results in reduction of ingestion. The conditioned taste aversion (CTA) is an associative learning between a gustatory stimulus (CS) and the stimulus related to sickness (US) with CR being the ingestive response (CR) to the tastant. CTA is adaptive because it protects animals from being killed by a poisonous tastant through the feed-forward preventive mechanism. The most effective CS is a novel and salient tastant $[26,27,38] . \mathrm{LiCl}$ is the most commonly used compound to induce US $[8,9,17,20,23,32]$. CTA is a robust association, even a highly preferred sucrose solution, could become rejected as a result of being paired to $\mathrm{LiCl}$ treatments $[33,34]$. It is a specific form of conditioning because of its associative specificity between the gustatory stimulus and the stimulus related to sickness [19].
It has been shown that pre-exposure to CS alone or to US alone can interfere with the formation of CTA [for CS pre-exposure effect see $7,22,25,44$; for US pre-exposure effect see $2,3,4,6,8,12,14$, $16,18,21,22,31,41,42,43]$. The pre-exposure to CS alone results in reduced associability between CS and US and the effect is known as latent inhibition. The US pre-exposure paradigm has been used to study whether two drugs share the common mechanism in a between-drug, or inter-agent, design; i.e. whether pre-exposure to one drug reduces the associability of the second drug [5]. Several hypotheses have been advanced to explain why the US pre-exposure retards the conditioning: (a) Tolerance hypothesis states that the preexposure weakens the conditioning efficacy due to the development of tolerance to the US drug $[10,11,21,30]$. (b) Habituation to novelty hypothesis states that US loses its saliency during the pre-exposure $[1,42]$. (c) Associative interference hypothesis states that the US has become associated to the context, thus blocking the formation of a new association in the same context a la Kamin's blocking paradigm $[6,29,37]$.

Cannon and his colleagues (1975) observed that (a) single US preexposure retards acquisition of the CS-US association, (b) the preexposure must occur within a limited period before conditioning, after 4 days there was no longer the effect, (c) the degree of disruption was a positive function of preconditioning US dosage and inverse function

"Corresponding Author: Dr. Andrew Chih Wei Huang, Department of Psychology, Fo Guang University, No. 160, Linwei Road, Jiaosi Shiang, Yilan County 26247, Taiwan, Tel: Tel: +886-3-9871000 (ext. 27114), E-mail: chweihuang@mail.fgu.edu.tw

Citation: Huang ACW, Hsiao S (2017) Unconditioned Stimulus Pre-exposure Interferes with Conditioned Taste Aversion in Rats. Int J Clin Pharmacol Pharmacother 2: 123. doi: https://doi.org/10.15344/2017/2456-3501/123

Copyright: (c) 2017 Huang et al. This is an open-access article distributed under the terms of the Creative Commons Attribution License, which permits unrestricted use, distribution, and reproduction in any medium, provided the original author and source are credited. 
Citation: Huang ACW, Hsiao S (2017) Unconditioned Stimulus Pre-exposure Interferes with Conditioned Taste Aversion in Rats. Int J Clin Pharmacol Pharmacother 2: 123. doi: https://doi.org/10.15344/2017/2456-3501/123

Page 2 of 6

of conditioning US dosage. They suggested that tolerance to the drug could not explain the effect because a typical tolerance requires many repeated treatments to develop, while the US pre-exposure effect occurred with only one single treatment. They conducted the CTA test in a new context to study the association hypothesis but did not obtain a context-dependent effect. Non context-specificity as well as the short lasting nature of the effect suggests that this is not an associative event.

There are three parameters that may affect the pre-exposure effect: (a) the property and intensity of pre-exposure agent, (b) the relative property and relative intensity of CS and US during conditioning, and (c) the duration (or persistence) between pre-exposure and conditioning. In the past, the parametric dose-effect has not been examined systematically (see the dose used so far by researchers in Figure 4). This study aimed to systematically manipulate the dose of US pre-exposure to observe, on one hand, the does-effect relationship and on the other hand, to see whether the hypothesis mentioned earlier was supported. In a series of experiments we used 10 doses of $\mathrm{LiCl}$, ranging from 0 (saline) to $72.32 \mathrm{mg} / \mathrm{rat}$, as the pre-exposure agent and a constant dosage of $\mathrm{LiCl}(7.632 \mathrm{mg} / \mathrm{rat})$ as the US in the conditioning phase, in an "intra-agent design", to study US preexposure and CTA relationship.

\section{Method}

\section{Subjects}

Subjects were male, Sprague-Dawley rats purchased from National Laboratory for Animal Breeding and Research Center in Taiwan, They weighed 250-350 $\mathrm{g}$ at beginning of the study. Rats were individually housed in wire-mesh cages in a colony room with 12-hr/12-hr day/ night cycle with temperature approximately 200C. All rats received lab chow ad libitum with water available for a limited duration as specified in the procedure.

\section{Apparatus}

All experiments were conducted in the experimental cage of the lickometer [DiLog Company; 15]. The lickometer recorded intake volume and timing of licking responses. However, in this report we used intake volume only to analyze CTA.

\section{Procedure}

\section{All experiments consisted of 4 phases.}

Preliminary Phase: All rats were adapted to a deprivation regimen with distilled water $\left(\mathrm{dH}_{2} \mathrm{O}\right)$ available for $30 \mathrm{~min} /$ day at approximately $1330 \mathrm{hr}$ in the colony room. Rats were then given $\mathrm{dH}_{2} \mathrm{O}$ for $15 \mathrm{~min}$ in the experimental cage and $30 \mathrm{~min}$ later given water for $30 \mathrm{~min}$ in home cages until the intake stabilized.

US Pre-exposure Phase: All rats were assigned randomly to treatment groups and given of various amounts of $\mathrm{LiCl}$ according to the following procedure; $\mathrm{dH}_{2} \mathrm{O}$ for $15 \mathrm{~min}$ followed by injection of various quantity $(\mathrm{ml} / \mathrm{kg})$ of $0.15 \mathrm{M} \mathrm{LiCl}$ (ip) (the isotonic concentration to minimize irritation), then, $30 \mathrm{~min}$ later, given $30 \mathrm{~min}$ of water in home cages.

Conditioning Phase: All rats were given $0.1 \%$ saccharin solution for $30 \mathrm{~min}$ followed by the injection of $4 \mathrm{ml} / \mathrm{kg}$ of $0.15 \mathrm{M} \mathrm{LiCl}$. This was repeated 3 times with one day of no treatment between sessions.
Extinction Phase: Rats were given the saccharin solution without any injection. This was repeated 2 times with one day of no testing between the tests.

The intake data on conditioning and extinction phases were converted into an index for "Measure of CTA" based on the following formula: $100^{*}$ (Intake Volume on a Test-Baseline)/Baseline for saccharin solution intake. The baseline was the saccharin solution intake volume of day 1 of the conditioning phase. Any decrease from this initial value was considered as an aversion. The amount of reduction was expressed as the percentage. Thus, a negative value indicated an aversion. A mixed analysis of variance (ANOVA) was used to evaluate the effect with $\boldsymbol{\alpha}$-level set at 0.05 .

\section{Results}

In Exp.1, a $2 \times 3 \times 3$ mixed ANOVA indicated (a) no difference between doses of 4 and $8 \mathrm{ml} / \mathrm{kg} \mathrm{LiCl}(\mathrm{F}(1,18)=0.04)$, (b) no difference between the number of days elapsed between the US pre-exposure and conditioning $(\mathrm{F}(2,18=2.73, \mathrm{p}>.05))$, (c) significant difference between 3 conditioning trials $(\mathrm{F}(2,36)=45.09, \mathrm{P}<.01)$, and (d) no interaction effects. Separate ANOVA between the control group and the groups given $\mathrm{LiCl}$ during pre-exposure indicated no significant difference. This lack of pre-exposure effect prompted us to conduct Exps. 2 and 3 by expanding the dose range widely.

Figure 1(a) shows that in Exp.1 the three conditioning trials induced a steadily stronger CTA, but there was no difference between the three dose groups. Figure 1(b) shows that the three duration groups did not differ significantly. The duration effect was tested further with the three groups in Exps. 2 and 3 that had the doses, 1, $16,32 \mathrm{ml} / \mathrm{kg}$, duration of 1 or 2 days.

ANOVA indicated no duration effect. Therefore, we combined the data in terms of doses, by collapsing over duration from all dose groups of 3 experiments to draw the dose-effect curve. Figure 2 shows the curve over 10 doses for 3 conditioning trials. A 3 by 10 ANOVA indicated significant dose effect of US pre-exposure $(F(9,80)=14.76$, $\mathrm{p}<.01)$, conditioning trials $(\mathrm{F}(2,160)=130.68, \mathrm{p}<.01)$, and their interaction $(\mathrm{F}(18,160)=1.70, \mathrm{p}<.05)$. Figure 3 depicts the curve over 10 doses during 2 extinction trials. A 2 by 10 ANOVA indicated significant dose effect $(\mathrm{F}(9,80)=7.42, \mathrm{p}<.01)$, trial effect ( extinction effect $)(F(1,18)=188.68, \mathrm{p}<.01)$, and their interaction $(\mathrm{F}(9,80)=3.99$, $\mathrm{p}<.01)$.

The lowest pre-exposure dose was a $0.5 \mathrm{ml} / \mathrm{kg}$ of $0.15 \mathrm{M} \mathrm{LiCl}$. We compared the CTA of this dose with the control group. A 2 by 3 ANOVA indicated a significant dose effect $(F(1,14)=5.71, p<.05$ ), conditioning effect $(\mathrm{F}(2,28)=20.84, \mathrm{p}<.01)$, but non-significant interaction $(\mathrm{F}(2,28)=0.02, \mathrm{p}>.05)$.

\section{Discussion}

In a study using a wide range of doses we found some important effect of US pre-exposure: (a) Pre-exposure to $\mathrm{LiCl}$ is effective in diminishing the ability of $\mathrm{LiCl}$ to induce CTA. (b) The pre-exposure effect occurred even at a low dose of $0.5 \mathrm{ml} / \mathrm{kg}$ of $0.15 \mathrm{M} \mathrm{LiCl}$, that is not effective by itself to induce a CTA [32]. (c) The dose-effect relation is overall positive, as the dose increases the effect increases; however, there seems to be at some intermediate doses the efficacy diminishes, thus the relationship appears to be not monotonic. (d) Upon repeated pairing of CS and US, the CTA effect steadily increased. 
Citation: Huang ACW, Hsiao S (2017) Unconditioned Stimulus Pre-exposure Interferes with Conditioned Taste Aversion in Rats. Int J Clin Pharmacol Pharmacother 2: 123. doi: https://doi.org/10.15344/2017/2456-3501/123

Page 3 of 5

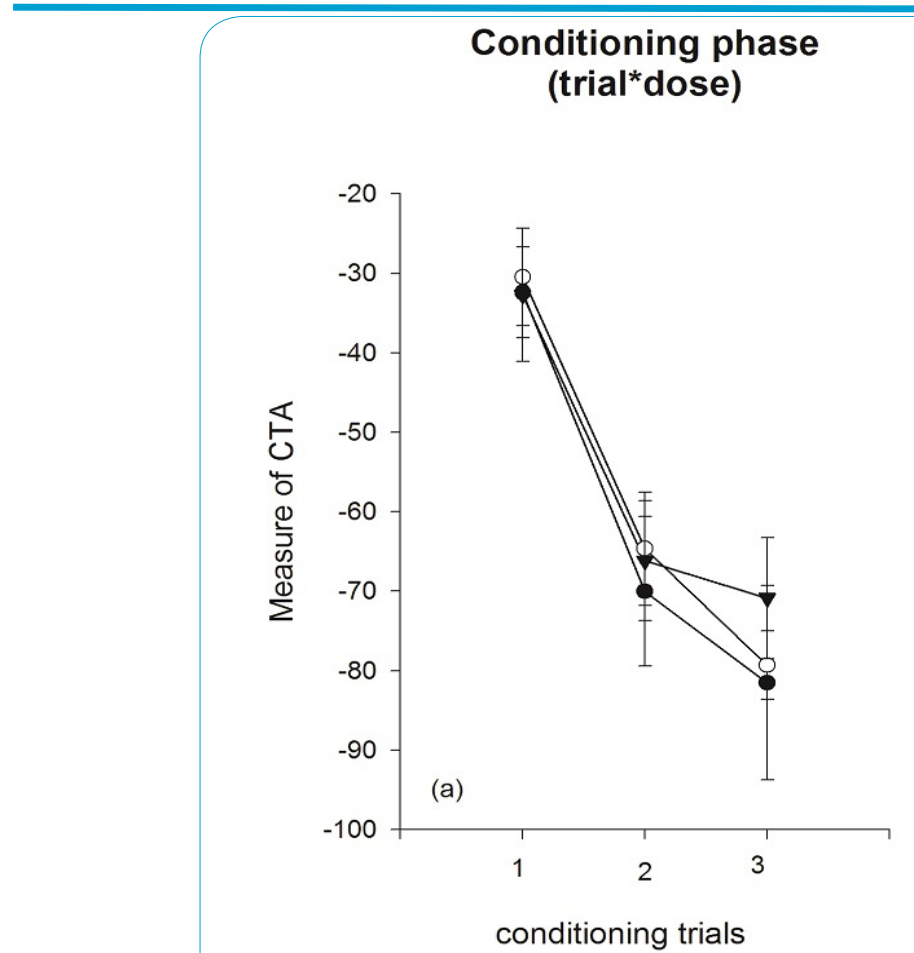

\section{Conditioning phase (duration*dose)}

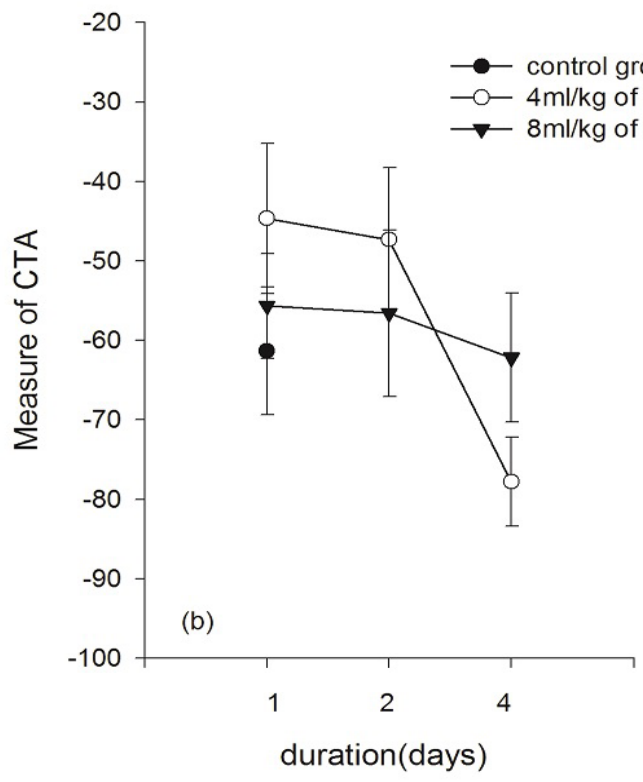

Figure 2a: The effect of US pre-exposure dose and the number of conditioning trials on conditioned taste aversion in Exp.1. Figure2b: The effect of US pre-exposure dose and the duration between the pre-exposure and the conditioning on conditioned taste aversion in Exp.1.

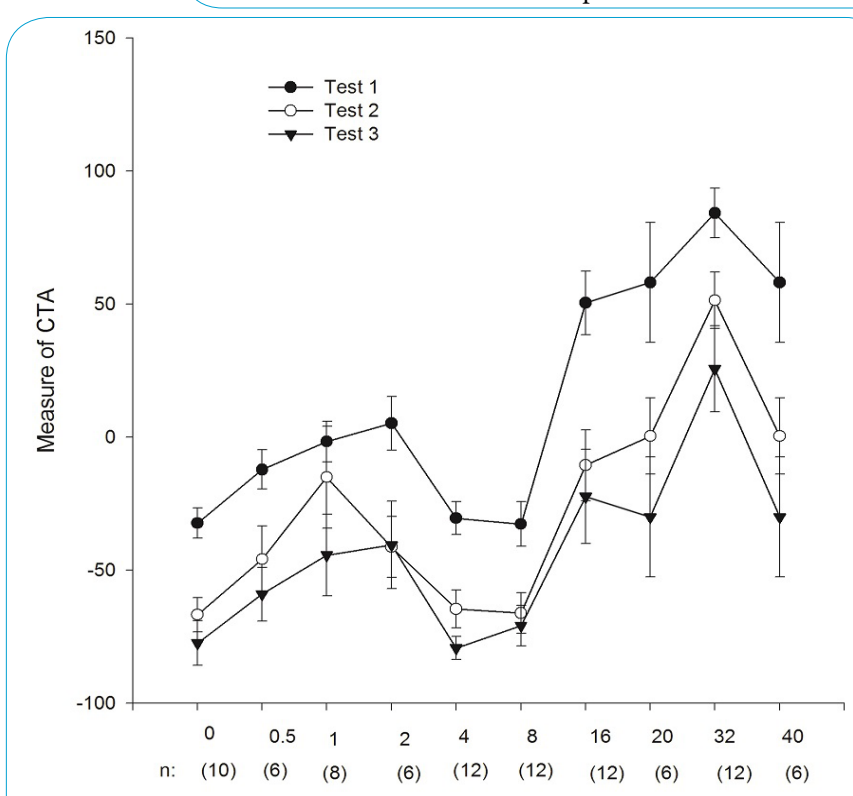

Dose of $\mathrm{LiCl}(\mathrm{ml} / \mathrm{kg})$

Figure 2: The dose-response relation between US pre-exposure and CTA. Note: Test 1 was a CTA test after one conditioning trial. Test 2 was a CTA test after 2 trials, and Test 3 was a CTA test after 3 trials. " $n$ " indicates the number of subjects used to obtain each mean value.

The dose range we used covered all those the previous studies employed. For example, $1.8 \mathrm{mEq}$ of $0.15 \mathrm{M} \mathrm{LiCl}$ (equal to $76.320 \mathrm{mg} /$ rat, assuming each rat's average weight being $300 \mathrm{gm}$ ) was used by Dacanay and Riley [14] and Ford and Riley [18]. Cannon et al [10] used $20 \mathrm{ml} / \mathrm{kg}$ of $0.12 \mathrm{M}, 0.36 \mathrm{M} \mathrm{LiCl}$ (equal to $30.528 \mathrm{mg} / \mathrm{rat}$, $91.584 \mathrm{mg} / \mathrm{rat}$, respectively). Batson and Best [2] used 10,20ml/kg of $0.15 \mathrm{M} \mathrm{LiCl}$ (equal to $19.080 \mathrm{mg} / \mathrm{rat}, 38.160 \mathrm{mg} / \mathrm{rat}$ ). Misanin, Hoefel, Riedy and Hinderliter [31]

Int J Clin Pharmacol Pharmacother ISSN: 2456-3501

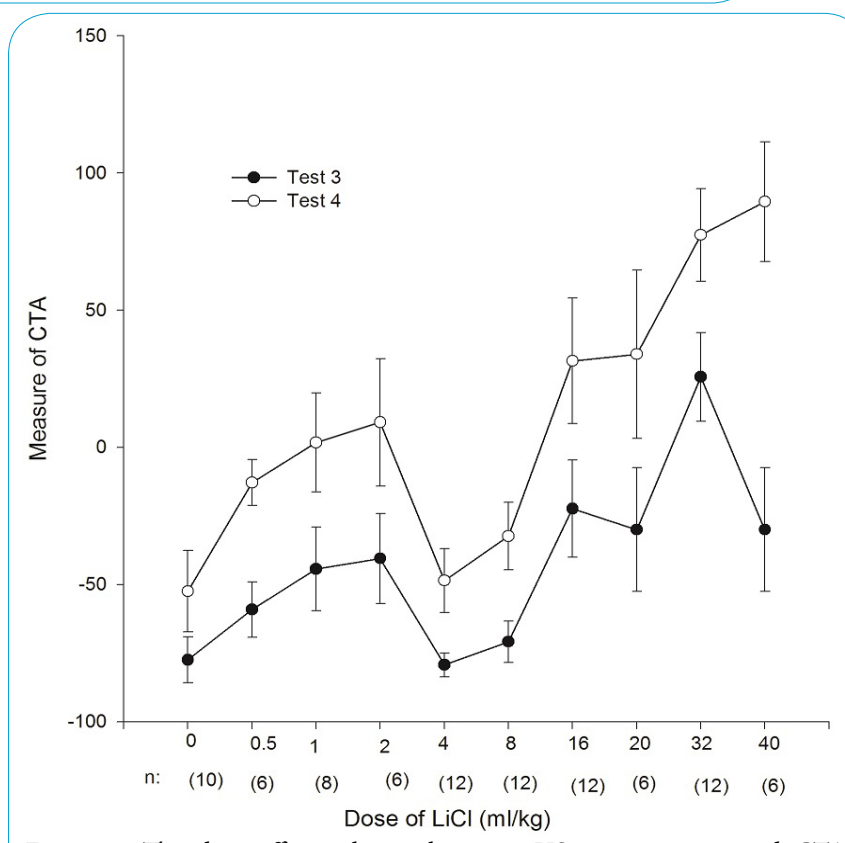

Figure 3. The dose-effect relation between US pre-exposure and CTA during the extinction phase. Note: Test 3 was a CTA test after 3 conditioning trials. Test 4 was a CTA test after Test 3, but no US was paired in Test 3. "n" indicates the number of subjects used to obtain each mean value. used $1 \%$ body weight IP injection of $0.15 \mathrm{M} \mathrm{LiCl}$ (equal to $19.080 \mathrm{mg} /$ rat). Overall, the lowest dose was $10 \mathrm{ml} / \mathrm{kg}$ of $0.15 \mathrm{M} \mathrm{LiCl}$ (i.p.) and highest was $20 \mathrm{ml} / \mathrm{kg}$ of $0.36 \mathrm{M} \mathrm{LiCl}$ that was administrated through intubation. Our result confirmed many of the studies.

Our non-monotonic dose-effect relationship parallels that of the inverted U effect of Randich and LoLordo [36] in one aspect. They showed, in a conditioned emotional response acquisition task, the 


\section{Dose-response curve}

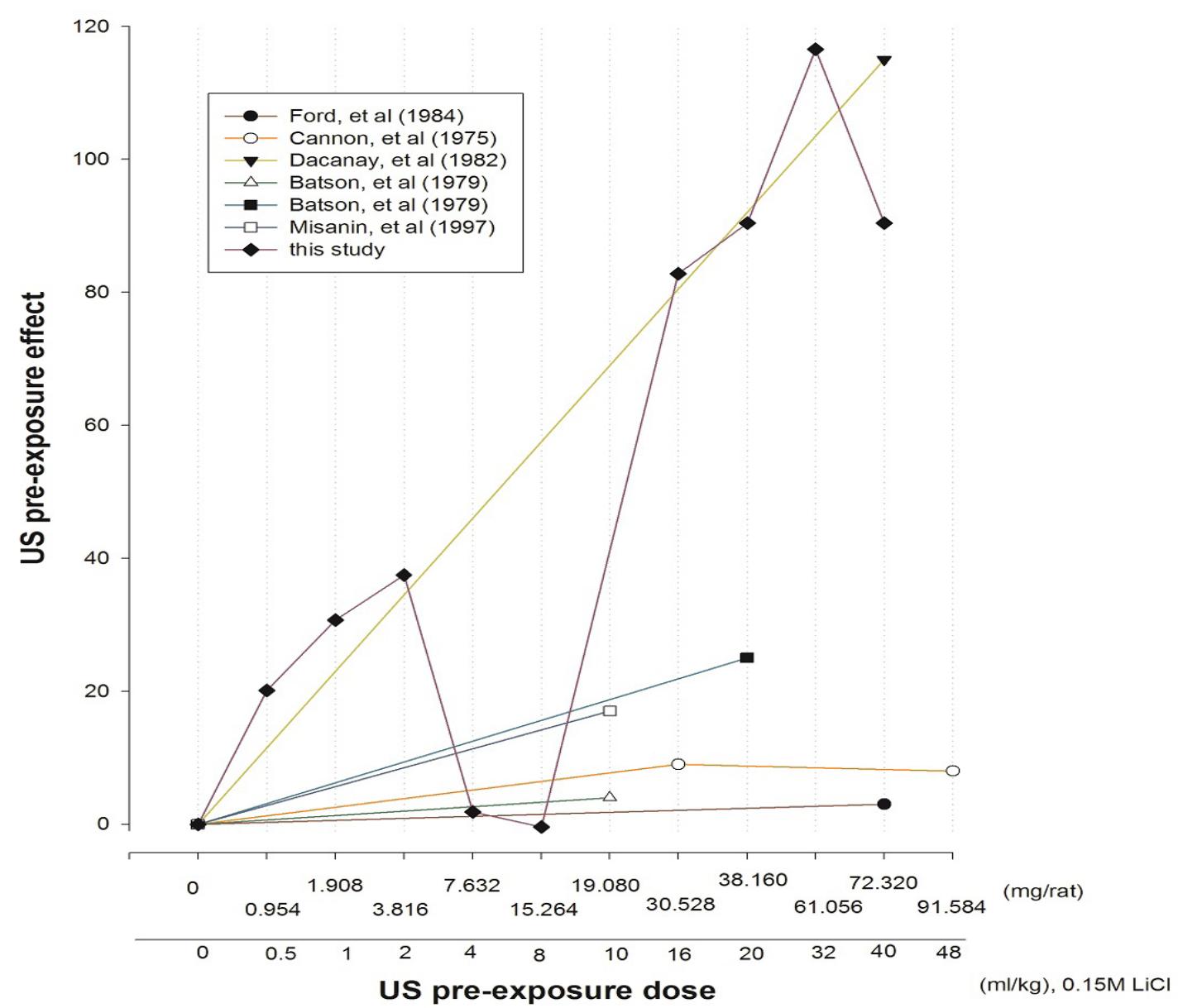

Figure 4: A general comparison of the dose-response relation between US pre-exposure and the effect on CTA of many studies. Note: The stronger the attenuation on CTA relative to the baseline the more the pre-exposure effect. Rat's average weight was assumed to be 300 gram in all experiments to facilitate comparison.

strongest attenuation occurred when the US pre-exposure strength was the same as that during conditioning. However, in our case the same dose between pre-exposure and conditioning resulted in the least attenuation of CTA. A tolerance, habituation, and associative blocking hypotheses would predict that the higher the pre-treatment the better the effect, thus the non-monotonic nature of the effect does not support these hypotheses. A drug tolerance usually requires many repeated treatments of a relatively high dose, while our pre-exposure effect required one a single treatment of very low dose. The associative blocking hypothesis is not supported also because the lowest effective dose was not strong enough, by itself, to induce a CTA. It is unlikely that this dose would form an association with the contextual cue to block the formation of CTA. The non-monotonic nature of the relationship also counters the associative hypothesis.

Figure 2 shows that the measure of CTA was more than zero in the high dose groups, indicating that rats ingested more saccharin solution than the pre-conditioning baseline even though the CTA procedure was applied. This indicates that US was not effective and that the increase in intake occurred because of the diminishment of taste neophobia to saccharin solution $[13,28]$. Overall, the acquisition of CTA and its extinction were quite predictable in all groups, i.e., upon repeated pairing of CS and US the CR intensified and when US was withdrawn CR weakened. Thus, it appears that CTA formation was not completely blocked by US pre-exposure and the associative potential of CS and US remained intact even in the highest dose group. The pre-exposure apparently affected the initial level of $\mathrm{CR}$ performance such that effect of first CTA conditioning was attenuated.

The primary physiological reactions to $\mathrm{LiCl}$ (UR) include diarrhea, tremor, lack of activity, lethargy, and unresponsiveness to stimuli [39]; however, the neuronal mechanism of the effect is unspecified. The development of conditioning and tolerance involves the secondary reaction to the UR, the compensatory responses, as well as the UR itself. Unless we specify the neuronal mechanism of the pharmacological effect of $\mathrm{LiCl}$, it is unlikely for us to be able to specify the compensatory mechanism. This non-pharmacological secondary effect is important in the development of a contingency-shaped effect that may be the bases in the US pre-exposure effect [35]. The mechanism of US pre-exposure effect remains to be uncovered.

\section{Competing Interests}

The authors declare that they have no competing interests. 
Citation: Huang ACW, Hsiao S (2017) Unconditioned Stimulus Pre-exposure Interferes with Conditioned Taste Aversion in Rats. Int J Clin Pharmacol Pharmacother 2: 123. doi: https://doi.org/10.15344/2017/2456-3501/123

Page 5 of 6

\section{Funding}

This research was supported by funding from the Ministry of Science and Technology, R.O.C. (MOST 105-2410-H-431-005) to ACWH.

\section{References}

1. Amit Z, Baum M (1970) Comment on the increased resistance-to-extinction of an avoidance response induced by certain drugs. Psychol Rep 27: 310.

2. Batson JD, Best PJ (1979) Drug-preexposure effects in flavor-aversion learning: Associative interference by conditioned environmental stimuli. $J$ Exp Psychol Animal Behav Processes 5: 273-283.

3. Berman RF, Cannon DS (1974) The effect of prior ethanol experience on ethanol-induced saccharin aversions. Physiol Behav 12: 1041-1044

4. Braveman NS (1979) The role of blocking and compensatory conditioning in the treatment preexposure effect. Psychopharmacology (Berl) 61: 177 189

5. Cannon DS, Baker TB, Berman RF (1977) Taste aversion disruption by drug pretreatment: Dissociative and drug-specific effects. Pharmaco Biochem Behav 6: 93-100.

6. Cannon DS, Berman RF, Baker TB, Atkinson CA (1975) Effect of preconditioning unconditioned stimulus experience on learned taste aversions. J Exp Psychol Animal Behav Processes 104: 270-284.

7. Cannon DS, Best MR, Batson JD, Brown ER, Rubenstein JA et al. (1985) Interfering with taste aversion learning in rats: the role of associative interference. Appetite 6: 1-19.

8. Cappell H, Le Blanc AE (1973) Punishment of saccharin drinking by amphetamine in rats and its reversal by chlordiazepoxide. J Comp Physio Psychol 85: 97-104.

9. Cappell H, LeBlanc AE, Endrenyi L (1973) Aversive conditioning by psychoactive drugs: Effects of morphine, alcohol and chlordiazepoxide. Psychopharmacologia 29: 239-246.

10. Cappell H, Le Blanc AE (1975) Conditioned aversion by amphetamine: rates of acquisition and loss of the attenuating effects of prior exposure. Psychopharmacologia 43: 157-162.

11. Cappell H, LeBlanc AE, Herling S (1975) Modification of the punishing effects of psychoactive drugs in rats by previous drug experience. J Comp Physiol Psychol 89: 347-356

12. Cappell H, LeBlanc AE (1977) Parametric investigations of the effects of prior exposure to amphetamine and morphine on conditioned gustatory aversion. Psychopharmacology (Berl) 51: 265-271.

13. Carroll ME, Dinc HI, Levy CJ, Smith JC (1975) Demonstrations of neophobia and enhanced neophobia in the albino rat. J Comp Physio Psychol 89: 457-467.

14. Dacanay RJ, Riley AL (1982) The UCS preexposure effect in taste aversion learning: Tolerance and blocking are drug specific. Anim Learn Behav 10: 91-96.

15. Davis JD (1990) Quick Lick [Computer program]. (Available from Dilog Instruments, 3124 Ortega Dr., Tallahassee, FL 32312, U.S.A.).

16. Domjan M, Best MR (1977) Paradoxical effects of proximal unconditioned stimulus preexposure: Interference with and conditioning of a taste aversion. J Exp Psychol Animal Behav Processes 3: 310-321.

17. Elsmore TF, Fletcher GV (1972) Delta 9-tetrahydrocannabinol: aversive effects in rat at high doses. Science 175: 911-912.

18. Ford KA, Riley AL (1984) The effects of LiCl preexposure on amphetamineinduced taste aversions: an assessment of blocking. Pharmacol Biochem Behav 20: 643-645.

19. Garcia J, Koelling R (1996) Relation of cue to consequence in avoidance learning. Psychonomic Science 4: 123-124.

20. Garcia J, Lasiter PS, Bermudez-Rattoni F, Deems DA (1985) A general theory of aversion learning. In Braveman NS \& Bronstein P (eds)., Annals of The New York Academy of Sciences 443: 8-21.
21. Goudie AJ, Taylor M, Atherton H (1975) Effects of prior drug experience on the establishment of taste aversions in rats. Pharmacol Biochem Behav 3: 947-952

22. Goudie AJ, Thornton EW, Wheller TJ (1976) Drug pretreatment effects in drug induced taste aversions: effects of dose and duration of pretreatment. Pharmacol Biochem Behav 4: 629-633.

23. Green KF, Garcia J (1971) Recuperation from illness: flavor enhancement for rats. Science 173: 749-751.

24. Hall G, Channell S (1986) Context specificity of latent inhibition in taste aversion learning. Q J Exp Psychol B 38: 121-139.

25. Hunt T, Amit Z (1987) Conditioned taste aversion induced by selfadministered drugs: paradox revisited. Neurosci Biobehav Rev 11: 107130.

26. Kalat JW (1974) Taste salience depends on novelty, not concentration, in taste-aversion learning in the rat. J Comp Physiol Psychol 86: 47-50.

27. Kalat JW, Rozin P (1970) "Salience": A factor which can override temporal contiguity in taste-aversion learning. J Comp Physiol Psychol 71: 192-197.

28. Kalat JW, Rozin P (1973) "Learned safety" as a mechanism in long-delay taste-aversion learning in rats. J Comp Physiol Psychol 83: 198-207.

29. Kamin LJ (1969) Predictability, surprise, attention, and conditioning. In Campbell BA \& Church RM (eds). Punishment and aversive behavior. Englewood Cliffs, NJ: Prentice Hall.

30. LeBlanc AE, Cappell H (1974) Attenuation of punishing effects of morphine and amphetamine by chronic prior treatment. J Comp Physiol Psychol 87: 691-698.

31. Misanin JR, Hoefel TD, Riedy CA, Hinderliter CF (1997) Remote and proximal US preexposure and aging effects in taste aversion learning in rats. Physiol Behav 61: 221-224.

32. Nachman M, Ashe JH (1973) Learned taste aversions in rats as a function of dosage, concentration, and route of administration of LiCl. Physiol Behav 10: 73-78.

33. Parker LA (1995) Rewarding drugs produce taste avoidance, but not taste aversion. Neurosci Biobehav Rev 19: 143-157.

34. Parker LA, MacLeod KB (1991) Chin rub CRs may reflect conditioned sickness elicited by a lithium-paired sucrose solution. Pharmacol Biochem Behav 40: 983-986.

35. Poulos CX, Cappell H (1991) Homeostatic theory of drug tolerance: a general model of physiological adaptation. Psychol Rev 98: 390-408.

36. Randich A, LoLordo VM (1979) Associative and nonassociative theories of the UCS preexposure phenomenon: Implications for Pavlovian conditioning. Psychol Bull 86: 523-548.

37. Rescorla RA, Wagner AR (1972) A theory of Pavlovian conditioning Variations in the effectiveness of reinforcement and nonreinforcement. In Black AH \& Prokasy WF (eds). Classical conditioning?: Current research and theory. New York: Appleton-Century-Crofts.

38. Revusky SH, Bedarf EW (1967) Association of illness with prior ingestion of novel foods. Science 155: 219-220.

39. Schou M (1958) Lithium studies. 1. Toxicity. Acta Pharmacol Toxicol (Copenh) 15: 70-84.

40. Skinner BF (1981) Selection by consequences. Science 213: 501-504

41. Stewart J, Eikelboom R (1978) Pre-exposure to morphine and the attenuation of conditioned taste aversion in rats. Pharmacol Biochem Behav 9: 639-645.

42. Switzman L, Fishman B, Amit Z (1981) Pre-exposure effects of morphine diazepam and delta 9-THC on the formation of conditioned taste aversions. Psychopharmacology (Berl) 74: 149-157.

43. Vogel JR, Nathan BA (1976) Reduction of learned taste aversions by preexposure to drugs. Psychopharmacology (Berl) 49: 167-172.

44. Wellman PJ (1982) Pre-exposure to flavor and conditioned taste aversion amphetamine and lithium reinforcers. Psychol Rep 50: 555-558.
Int J Clin Pharmacol Pharmacother

ISSN: 2456-3501
IJCPP, an open access journal Volume 2. 2017. 123 